\title{
The Didactic Construct of Design Technologies in the Educational Process of Modern University \\ Tatyana M. Kozhanova
}

Chuvash State Pedagogical University named after I.Y. Yakovlev, 428032, Cheboksary, Russia

Email: koganova2003@mail.ru

Boris A. Karev

Amur State University, 675027, Blagoveschensk, Russia

Guzel Z. Khabibullina

Kazan (Volga region) Federal University, 420008, Kazan, Russia

Ibragim D. Ibragimov

Pyatigorsk State Linguistic University, 357532, Pyatigorsk, Russia

Lyutziya G. Khisamiyeva

Kazan National Research Technological University, 420015, Kazan, Russia

Natalya V. Zaytseva

Mariya A. Kulkova

Kazan (Volga region) Federal University, 420008, Kazan, Russia

\section{Doi:10.5901/mjss.2015.v6n2s3p225}

\section{Abstract}

The relevance of the problem of arranging the educational process in modern university using design technology remains one of the most demanded in educating the future experts for modern production. Therefore, the objective of this article is to submit a scientific rationale for the didactic construct of design technologies in higher educational process as a productive educational model focused on educating a student's personality - a future professional demanded by today's job market. The paper submits theoretic and methodological foundations for designing and implementing project technologies into the university educational process, the nature and structure of the didactic construct of these technologies as a system category (the learning objectives, syllabus, the means of pedagogical partnership including motivation and teaching tools, arrangement of the educational process, the subjects of the learning process, the results of the activity and the level of professional proficiency). The article submissions may be useful for the teachers of educational institutions in the system of continuing professional education, young scientists, post graduate students, the university counselors, the attendants of the advanced training and retraining courses. It is also recommended for undergraduates and students participating in the research work.

Keywords: a didactic construct of design technologies, modeling, monitoring, a design approach, design technologies, the typology of design technologies.

\section{Introduction}

\subsection{The relevance of the issue}

Modern processes of change taking place in the educational process of a university are determined by the search for qualitatively new approaches to educate a new generation demanded by the society as active subjects of different social 
strata, by the labor market as competent, creative professionals, as a personality like "Self" with the developed abilities of self-identification and self-realization. For this matter, the long-term goal of the educational process in higher education as emphasized in the Federal State Educational Standards of higher education (FSES, 2009), is the transformation of subject knowledge from the main objective of the educational process into a means of development of real competences of design, self-identity, self-determination, self- education and actualization of the university graduates in the labor market. According to the leading experts research in design and innovative educational technologies implementation (Verbitskiy, 1999; Grebenuk, 2000; Zinchenko, 2002; Ibragimov, 2012; Novikov, 2000; Selevko, 1999; Slastenin, 2003; Vlasova et al., 2015; Khutorskoiy, 2001; Schedrovitskiy, 1993; Yakimanskaya, 1996; Mokeyeva et al., 2015; Khairullina et al., 2015) the focus of higher education on the development of such kind of a person determines a qualitatively new didactic structure, organization, learning technologies and their management on the basis of design approach that is characterized by intensification of the simulation, design and construction functions. The design approach to the university educational process supports a multi-level system of achieving didactic objectives through detailed exploration of the learning - cognitive problems, intention, situations that result in tangible, practical outcome. The practical result (a design product) is presented through reports, abstracts on a given topic, essays, research projects, articles for the students' scientific conferences, youth grants, computer programs and other types that are determined by the educational syllabus. Within the design approach the innovative technology is not only a specific sequence of procedures that arrange learning activities to achieve the targeted educational objectives but primarily the organization of learning activity to build its product according to the law of cultural assimilation in the development of design culture elements (Zeer, 2000 ). The university student appears consistently in the design space, because he is obliged to design something constantly: his own very self, the trajectory of education and professional activity, living space, family and other.

\subsection{The theoretical and methodological background of the didactic construct of design technologies in higher educational process}

The theoretical and methodological novelty of the didactic construct of design technologies in higher educational process is determined by the whole range of priorities transformation of the university educational process where the quality training of the specialists who are demanded in the changing labor market, their competitiveness in the economy and production sectors is the highest priority. The demand for such specialists brings to reconsideration of the theory and practice of the university educational process, learning objectives, principles, functions, syllabus, and technology of teaching students by means of the research - based approaches that meet the needs of the age. These trends are observed in the requirements of the Federal State Educational Standards (FSES )and other legal and teaching materials (FSES of higher education, 2009; Law on Education, 1996). The state of the theory and practice of educational process in higher school also emphasizes the need and timeliness of the design approach development to update the didactic construct of design technologies as an innovative direction in the educational process, where the objective of creating a "design personality", with design thinking, able to address the problems and solve them both in everyday and unpredicted and unusual situations. The essence of the design - based approach (Clarín, 1995; Makhmutov, 1993; Zimnyaya, 2003) is presented through the objectives, syllabus and training technologies for the university students including:

1) the technological criteria generally accepted in educational theory and practice:

- conceptuality that is constructed on the interdisciplinary basis, supported by personality - oriented concepts allowing to determine the objectives and values of design culture;

- systemacity is the characteristic of a system: the logic of the educational process, integrity, interactions between its parts, interaction with environment;

- manageability is determined by the possibility to design and correct the implementation stages of project activities, plan and anticipate the targeted results, provide pedagogical support and tutor the students in this activity gradually elaborating the educational challenges and tasks;

- reproducibility is determined by an opportunity for recycling the techniques, methods and procedures of other teachers in various disciplines in identical conditions.

2) The didactic particularities of the technological process:

- Work organization (setting the objective, determining the "field of problem", specifying the ideas, project planning, drawing up a long-range plan, creating work groups, setting the rules and restrictions for the project activity participants);

- the selection of teaching materials, rethinking of teaching methods and means;

- designing the methods, techniques, forms, partnerships strategies (teacher - student - small group), managing group processes, reflexive activity; 
- analyzing the group dynamics, a prominent experience of using design technology, reflection over the results;

3) The foundation on the didactic principles, syllabus, procedures, problem-based teaching focused on such an organization of educational process that involves producing teacher-guided problem situations and students' independent activity to solve them:

- determination of the problem that makes the framework of project activity. The problem is not offered to students available but through a variety of teaching methods, visual aids they are brought to its statement, hypotheses identifying its solution through the problem situation;

- using the procedural nature of the technology: a problematic situation - a problem - the problem tasks of its resolution. The problematic situation is stated on the basis of real phenomena of social or personal experience. The problem may be presented in a sufficiently explicit or implicit form. This is determined by the level of students' preparedness for such activities, as well as their independent cognitive activity;

- implementing different levels of problematicity: the first level is related to the teacher's representation of the material being studied; the second level - the teacher creates a problematic situation himself and helps the students to solve it; the third level - the teacher creates a problematic situation and the students solve it; the fourth level is characterized by the students' complete independence while identifying the problem, its solution and settling.

Analyzing different levels of problematicity the experts (Zimnyaya, 2003; Makhmutov, 1993) pay attention that the highest level of problematicity inherent in learning when the students themselves identify the problem (task), find a solution themselves, settle and self-check on the solution. The project activity is implemented at the fourth level. At the previous three ones the students get ready for such activities: to realize the problem (use the knowledge and skills to understand the educational information provided in the form of text, diagrams, charts, formulas, tables, integrating information from different sources), to characterize the problem (define variables of the problem and relations between them, to build hypotheses, evaluate information critically), to present the problem (to develop the form of presenting the information, to move from one kind of presentation to another), to solve the problem (to make decisions according to the terms of the problem, analyze, plan to achieve the goal ), to reflect on the decision (to analyze the obtained solution and, if necessary, seek for further information, to critically evaluate the decision), to present the solution of the problem (choose the form of the result presentation and its clarity).

\subsection{The background of the problem in the theory and practice of pedagogy}

The theoretical - methodological basis of the research includes the works by the didactics specialists (Bespal'ko, 1995; Grebenuk, 2000; Ibragimov, 2011; Makhmutov, 1993; Khutorskoiy, 2001), the specialists in design and implementation of innovative technologies (Zeer, 2000; Zimnyaya, 2003; Novikov, 2000; Polat, Bukharkina, 1997; Selevko, 1998), the researchers in theoretical - methodological approaches to modeling the project-based education (Zimnyaya, 2003; Ibragimov, 1912; Pakhomova, 1997).

The theoretic basis contains the key concepts (design technologies, the didactic construct of design technologies, design approach, the typology of design techniques, modeling, monitoring); the system of design approach principles (the principle of personal goal-setting, the principle of interdisciplinarity, the principle of integration, the principle of harmonization, the matching principle, the design principle, the principle of self-determination, the principle of correction), as an expression of didactic categories in specific forms, methods, teaching tools, forms of organization of students' purposeful activity to acquire the specific content in a particular field of knowledge and professional activity; the innovative conditions of university educational environment (the conceptual ideas of design approach, the didactic construct of design technologies (types, structure, content, criteria-based assessment, results); a scientific - methodological support of project technologies implementation).

\section{Methodological Framework}

\subsection{The key concepts}

The qualitative and quantitative parameters of the study results have reflected in the process of updating the discursive content of the key concepts:

- a didactic construct is a system of didactic objectives, principles, functions, syllabus oriented on the results of creative personality development in the educational process; 
- a didactic construct of project technology is the design mechanism for organizing learning activities of the university students to achieve targeted results, based on a system of objectives, principles, syllabus, procedures of problem-based learning enriched with the ideas of productive project activity: problem determination, identifying the "field" of the problems, specifying the ideas ; project planning, scheduling the project; the participants' independent work over the individual or group research as well as on creative tasks; the intermediate discussion of the obtained results in groups (in classroom, the classroom in the scientific community, in computer room, library, etc.); defending the project, reviewing, presentation; brainstorming, expertise, announcement of the results of external evaluation, stating the conclusions;

- Modeling - a method of objects, processes and phenomena research on the basis of their reconstruction, identically reproducing the simulated objects and ensuring accessibility for their thorough and comprehensive study;

- monitoring is a continuous monitoring over a process, phenomena, object to identify its compliance with the desired result or original assumption; in educational theory and practice - a systematic diagnostic monitoring of the educational process, personality development, design of the innovation systems, etc.;

- a project technology is a flexible learning model in university as a complete cycle of training activities. In other words it is a project based on didactic principles, content, procedures of problem-based learning with all the attributes of project activity;

- a design approach is an innovative solution of the problems described in the Federal State Educational Standard of higher vocational education (FSES ) requirements for long term while implementing the didactic objective through the detailed study of the problem, intention, situation that result in tangible practical result ready for implementation;

- the typology of projects is the projects classification based on typical characteristic of a certain type.

\subsection{Principles}

The system of principles we have applied during the research:

- Personal goal-setting that means focusing on student's personality - a future specialist of modern production;

- Integration that means orienting the learning objectives towards professional objectives;

- Harmonization of the educational process requirements to the student with the production requirements to the personality of a future specialist;

- Conformity of the content of the subject didactic units to the design competencies reflected in the prediction model of a specialist (job description, psychogram, tehnogram);

- Designing for the development of common cultural and professional competencies needed for the research, design, developing, creative educational activity of the students;

- Self-determination which is manifested in the design of the individual trajectory of self-determination, selftransformation, independance, self-realization in vocational activities, providing value orientations in accordance with personal aspirations;

- Correction which provides clarification of the didactic units of studied disciplines cycles in the university curriculum and pragmatic reduction (trade) of the focus of professionally-important competencies recommended by the manufacture.

\subsection{Conceptuality of educational milieu}

A characteristic feature of the educational milieu of the university focused on using the didactic construct of design technologies in educational practice is its theoretical - methodical provision of design ideas: a scientific substantiation of the objectives and tasks of students' training; the principles of selecting and structuring the educational material; determination of theoretical knowledge, improving fundamentalization of training and practical knowledge forming the basis of professional competence; the development of interdisciplinary relations in the related fields of professional activity; identification of the integrative relations of professional knowledge with other sciences (engineering, scientific, liberal) and determination of professional knowledge as a single package; identifying the syllabus basic components: an invariant part as a block of technical objects, production technologies, etc. that is new and promising for modern production (industry); a professional part uniting the professionally-oriented knowledge selected according to the groups of professions; a specialized part including the concepts and theories selected according to the students' specialization; a worldview part uniting liberal, professional, specialized and practical disciplines cycles providing ideological direction of 
knowledge.

The application of theoretical foundations, searching for the ways to address them in particular academic and practical activities, in creating a targeted "product" enable students to understand the importance of theoretical knowledge in practical solution of problematic situations. This is the didactic nature of project activity, its didactic role in project technologies implementation.

\section{Results and Discussions}

\subsection{The typology of the didactic constructs of design technologies}

It is determined by:

- the project dominant activities (research, exploration, creative, role-playing, practice - oriented, informative, etc.);

- the substantive areas: a mono-construct (within a single field of knowledge), an interdisciplinary construct (within a variety of disciplines);

- the character of coordination: direct (rigid, flexible), hidden (implicit, simulating the project participants);

- the character of contacts (among the participants of one institution, city, region, country, different countries);

- $\quad$ the number of participants;

- the duration of the project.

In accordance with the project dominant activity we have identified the following types of didactic constructs of design technologies:

- the research type is subjected to the logic of research and have a structure that is close or completely coincides with a genuine scientific research. This type of construct suggests argumentation of the topic relevance, research problem definition, setting the tasks, methods, sources of information, the choice of methodology, hypothesizing, developing the ways to solve it (experimental, pilot), discussing the findings, conclusions, presentation of the results, estimating new challenges for further research development;

- the creative type - any construct can be called creative. While determining the creative type, it is reasonable to select its dominant aspect (a collective newspaper, video, writing, theatrical, celebration). The presentation of the result requires a well-defined structure in the form of a movie script, a celebration program, a writing plan, etc.;

- the role, game type - the structure of these types remain open until the end of work. The participants take up a role according to the nature and content of the construct. It can be both fictional and virtual characters that simulate business, social relations developed by the participants of the situation. The results are projected at an early stage of implementation. They show a high degree of creativity;

- the information type is aimed at collecting information about the object, phenomenon. For its implementation it requires a well-designed structure, organizational environment, systematic correction as the work advances. The structure of this type is expressed as follows: the objective of the construct, the relevance of information sources (literary, mass media and databases: the Internet, interviews with partners, "brainstorming" etc.), information processing, result, presentation;

- the practice - oriented type is distinguished by the initially outlined result of the activity to implement the students' personal interests (a document drafted upon research results in ecology, biology; the documents of professionally - significant, historic, literary character), recommendations to eliminate the discrepancies found. For example, the draft law on environment protection, students' language vocabulary and others. Such constructs require an elaborate structure with the functions distribution for every participant, clear conclusions, a presentation including personal contribution of every participant.

According to the substantive area we have identified:

- the mono-construct type is carried out within a single subject. In this case the most complex areas of the subject or the key problems of the course are selected. It requires a clear structure, specifying the competencies that will be formed as the result. The logic planning of the training sessions and the forms of presentation are developed by the students and often the work on such constructs is further continued in scientific community;

- the interdisciplinary type is usually held in extracurricular time. This is either a small-scale projects involving two - three subjects, or advanced long-term ones intended to solve a complex problem for all the participants. They require coordination of both teachers and students having clearly defined the tasks, well-designed forms 
of intermediate and final presentations.

According to the character of coordination we found out:

- the types of open, explicit coordination. In such constructs a coordinator performs his own function guiding the work of the participants, organizing if necessary, the activities of individual performers. For example, if you want to arrange an interview in an official institution, invite experts, etc.;

- the hidden coordination type (this mainly relates to telecommunication projects). In such constructs the coordinator reveals himself neither in any networks nor in the activity of group participants. It acts as a full member (one of...). These types can be exemplified with famous telecommunication projects: "Pravo Golosa" (" A Right to Vote"), " Modnyj Prigovor " ("Fashion Verdict") and others.

- According to the character of contacts we have determined:

- the domestic or regional contacts (within a country). These constructs are interdisciplinary, organized either within a single institution or between institutions within the region, the country;

- the international (the participants are from different countries). This type is of exceptional interest, but its implementation requires electronic information technologies.

The construct according to the number of participants includes the types: personal (between two parties located in different educational institutions, countries, regions); pair (between the pairs of participants); group (between the groups of participants). From the methodological point of view the organization of students' group activities depends greatly on the teacher.

According to the duration time we have pointed out: short-term (to solve minor problems or a part of a major problem), which can be developed on the basis of several classes of one subject or on an interdisciplinary basis; medium-term (from a week to a month); long-term (from one month to several months).

As a rule, the work over the short-term types is held in a single subject classroom involving sometimes knowledge from other disciplines. As for the constructs of medium and long term they -- traditional or telecommunication of regional or international character - are interdisciplinary and contain a significant problem or several interrelated problems, and therefore may represent a package of constructs. As a rule, they are conducted outside classroom, although their elements are used in the classroom either.

The results of the study performed indicate that in real learning process the universities use mixed types of didactic constructs of design technology including research, creative, substantive, practice oriented and information elements at the same time. Every type is characterized by one or another form of coordination, deadlines, stages, number of participants and others.

\subsection{The classification of the didactic constructs of design technology.}

The classification is determined by the grounds presented in the typology of design technologies. But above all the didactic construct of design technology reflects the logic of student and teacher activities. Student activities in connection with this logic appear as a system of educational projects: any academic program for the student is a training project, the study of particular courses is also a training project (the subprojects in relation to the main project - a curriculum). The activities of the teacher are structured in a similar way - it supposes implementation of pedagogical projects (Novikov, 2000). The didactic constructs of design technology thus should reflect the three levels of activity: acquiring the curriculum, the subject curriculum, the topics. In the educational environment of modern university the academic time becomes the determining factor of constructing a didactic construct of the technology. The major training project (a curriculum) is divided into sub-projects (according to the year of study for a Bachelor's, Master's and specialist's degree: a training project of the first, second, etc. years of study). On the same grounds the annual training project can be divided into one-semester training project then into subject projects and then - a project as a specific training session (Ibragimov, 2012). Accordingly we have classified the didactic constructs of design technologies:

- Factual constructs are productive in the process of studying the ideas, concepts, facts in the subject educational modules of all cycles;

- Modular constructs are independent training projects that are included into basic curriculum;

- Mono-subject constructs exist in the form of independent courses on compulsory or optional basis;

- Interdisciplinary constructs - long-term, integrated design technologies including the study of training material from different subjects, fields of science and production;

- Reflective constructs are focused on evaluation of the implemented technologies, the decision on their productivity or correction and continuing the pilot. 


\subsection{The stages of drafting a didactic construct of design technology}

As a result of the performed research we have established the scientifically -proved stages of drafting a didactic construct.

The pre-drafting stage means introduction into the project activities. Its task is to predetermine the success of the second stage - implementation of the didactic construct. It is achieved through the logical sequence: diagnostics, problematization, goal-setting, conceptualization, formatting, pre-socialization of the construct.

The diagnostics is carried out in the process of relating the education to real life, cognition and profession problems. It provides a living, creative interest of the participants in identifying the problems, a high degree of freedom of search in surrounding and information environment, access to relevant information, equipping the participants with the ways to explore reality, the opportunity to exchange views with fellow students, psychological readiness to keep the impression of studying in mind, etc..

Problematization is valuable self-determination of students in the problematic field of studied content. The discovery of a new problem becomes a serious motif to be included in the project activities. Problematization includes the steps to identify conflicts, the "field of problems, defining a general problem, creating a "tree of objectives", their systematization and hierarchization.

Conceptualization refers to the methodological level. The accuracy of the design concept depends on clear understanding of the range of categories, concepts, ideas, definitions which will describe the phenomena and processes within the construct.

Specification of the objective. The objective plays a stimulating (regarding the participants), transformational (regarding the subject of design and its parts), regulating (regarding the activity and its results), orientation (regarding the final product) role. After specifying the objective, one should develop a strategy of design technology which determines the overall direction and character of achieving.

Formatting the didactic construct of design technology is a way of restricting (regulating) the project participants' activity by setting its boundaries and scale. A scientifically -grounded choice of the format includes the regulations on time, space, context, membership and other parameters. Their number varies according to the pedagogical situation and the purposes of developing the construct.

Pre-socialization means the procedure of public presentation of the didactic construct. At this stage the experts decide on admission of members to implement the planned construct or to reject it.

Implementation stage. If the pre-project stage was implemented entirely, every participant can start the planned action and approach the assigned tasks. At the stage of implementation every design element is determined by the logic of creating or transforming the object of design and is always geared to specific targets coordinated at the pre-stage. The members must clearly understand their objectives, expect the results and their significance in the overall concept of design technology.

The work at the final stage includes two main procedures that are different in the technology but converge in terms of functionality. These are the expertise and reflection. The expertise is conducted by involving the independent experts; in the course of (self-) evaluation of the results according to the selected criteria; as a part of reflection on the success and integrity of design as a joint activity including its objectives, content, forms, methods of implementation; while reflection on design as a technology built according to certain rules.

The reflective stage includes an assessment of not only material but also human result. Metaphorically it can be called "The Lessons of didactic construct of design technology." Under correct organization it has the greatest educational impact. Primarily reflection concerns the course of project activities and the settled system of relations. Reflection on the output of the project activity is an appeal of the participants to themselves and each other in a new way, from the height of the acquired experience of joint activities. In final reflection the time of design technology seems "looped". It is vision of oneself from aside - "here and now". This is a retrospective view over the course passed. This is also a view into the future.

The productivity of implementing the didactic construct of the project technology is confirmed by the results of the experimental work in the universities educational practice in the process of curriculum transformation, syllabus, training constructs package (recommendations, constructs scenarios). The expert assessment of project activities of the students participating in the study significantly increases the level of knowledge application (their solidness, scope, stability, consistency, integrity), general cultural and professional competencies (using knowledge, designing personal professional strategy, the choice of axiological alternatives, willingness to self-transformation, changing socio professional priorities, creativity). The survey results are presented in table 1. The dynamics of students' design competencies." 
Table 1. The dynamics of students' design competencies (data in \%\%)

\begin{tabular}{|l|c|c|c|c|}
\hline Indexes & \multicolumn{4}{|c|}{ Groups } \\
\hline & $\mathrm{EG}(1 \mathrm{K.})$ & $\mathrm{EG} \mathrm{(3} \mathrm{\kappa .)}$ & $\mathrm{CG}(1$ к.) & CG (3 к.) \\
\hline Knowledge application & 31,0 & 43,0 & 25,9 & 34,7 \\
\hline Designing a personal- professional strategy of activity & 20,3 & 32,0 & 20,5 & 23,6 \\
\hline Axiological choice & 20,3 & 28,7 & 25,6 & 30,2 \\
\hline Self-transformation in design activity & 18,7 & 25,6 & 20,7 & 23,1 \\
\hline Creativity & 34,3 & 49,2 & 218,0 & 19,0 \\
\hline
\end{tabular}

Notes: EG - an experimental group, CG - a control group

\section{Conclusion}

The theoretic and practical relevance of the research is determined by the established structure of university education focused on the implementation of advanced technologies that meet the needs of society, labor market and the claims of the individual. The results of the study indicate that the structure, content and procedural aspects of the didactic construct of project technology is also consistent with the principles of synergistic modernization of the university educational process: interdisciplinarity, self-transformation of the individual in project activity, readiness to productive activities based on performing individual actions from goal-setting to self-control and self-esteem. This trend indicates a significant extensive and intensive educational potential of the didactic construct of design technologies important for the development of synergetic, advanced forms of university students' education.

\section{References}

Bespal'ko, V.P. (1995). Pedagogy and advanced learning technologies. Moscow.

Federal State Educational Standard of higher education for the degree program. (2009). Moscow.

Grebenuk, O.S (2000). Pedagogy of individuality: a course of lectures. Kaliningrad.

Ibragimov, G.I. (2011). Learning theory. Moscow.

Ibragimov, G.I. (2012). The concept of didactic teacher training: design - technological approach. Kazan.

Khairullina E.R., Valeyev A.S., Valeyeva G.K., Valeyeva N.S., Leifa A.V., Burdukovskaya E.A., Shaidullina A.R. (2015). Features of the Programs Applied Bachelor Degree in Secondary and Higher Vocational Education. Asian Social Science; Vol. 11, No. 3, 213217.

Klarin, M.V. (1995). The innovations in the world pedagogy. Riga.

Makhmutov, M.I. (1993).The educational technologies of students' thinking development. Kazan.

Mokeyeva E.V., Zakirova V.G., Masalimova A.R. (2015). Tolerant Pedagogic Space as a Condition of Non-Violence Position Education among Elementary School Pupils. Review of European Studies, Vol. 7, No. 4, 216-220.

Novikov, A.M, Novikov, D.A. (2004). Educational project (methodology of educational activities). Moscow.

Novikov,A.M. (2000). Russian education in the new era. The paradoxes of Heritage. The vectors of development. Moscow.

Pakhomova, N.Yu. (2003). The methods of training project in educational institutions: A Handbook for Teachers and Students of teacher' training universities. Moscow.

Polat E.S., Bukharkina M.Yu. (2007). Modern teaching and information technologies in education system. Moscow.

Schedrovitskiy, P.G. (1993). Essays on the philosophy of education. Moscow.

Selevko, G.K. (1998). Modern educational technologies: a manual for teachers' training universities and further training. Moscow.

Slastenin, V.A., Isaev, N.F., Shiyanova, E.N. (2003). Pedagogy. Moscow.

The Federal Law on Education in Russian Federation (1996). Moscow.

Verbitsky, A.A. (1999). New educational paradigm and contextual learning. Moscow.

Vlasova V.K., Kirilova G.I., Masalimova A.R. (2015). Information and Logistic Foundations of Pedagogical Education Design and Content Education. Review of European Studies, Vol. 7, No. 4, 54-58.

Yakimanskaya, N.S. (1996). Personality - oriented education in modern school. Moscow.

Zeer, E.F. (2000). Psychology of personality - oriented professional education. Ekaterinburg.

Zimnyaya, I.A. (2003). The key competencies - a new paradigm of education result. Vysshee obrazovanie segodnya. 5.34 - 42.

Zinchenko, V.P (2002). The psychological foundations of pedagogy. Moscow. 